\title{
Contemporary national trends of cystic fibrosis hospitalizations and co-morbidities in the United States
}

\begin{abstract}
Introduction: Cystic fibrosis (CF) is a life-limiting multisystemic genetic disease. Patients with CF have a high rate of hospitalization. We attempt to ascertain national trends of inpatient stays, prevalence of various co-morbidities during hospitalizations, outcomes and discharge disposition among CF patients.

Material and methods: Data from the National Inpatient Sample (NIS) was used to identify all hospitalizations of patients with CF and their demographic characteristics from 2003 to 2013. Prevalence and effects of various co-morbidities like acute kidney injury (AKI) were determined. Detailed sub-group analysis was performed for individuals with lung transplant.

Results: The annual rate of hospitalization per 1,000 CF patients in the U.S. increased from 994 in 2003 to 1,072 in 2013. The overall in-hospital mortality was 1.5\%; median age at death was 27 years. In-hospital mortality trended down from $1.9 \%$ to $1.2 \%$ from 2003 to 2013 ( $p$-value for trend: 0.002). The median length of stay was 7 days. The prevalence of chronic liver disease and AKI was $3.7 \%$ and $3.8 \%$ respectively. Multivariate adjusted odds of mortality for AKI was $1.74(95 \% \mathrm{Cl} 1.57-1.93, \mathrm{p}<0.001)$. Patients with prior lung transplantation accounted for $6.5 \%$ of hospitalizations. These patients had a significantly higher prevalence of AKI.

Conclusions: The annual hospitalization rates of CF patients is increasing over the years. Females with CF constitute a higher proportion of hospitalized patients despite a higher male preponderance of males with CF in the community. AKI is associated with a significantly higher in-hospital mortality. Lung transplant recipients have a higher prevalence of AKI and mortality.
\end{abstract}

Key words: cystic fibrosis/mortality; lung transplantation/mortality; acute kidney injury; national inpatient sample

Adv. Respir. Med. 2016; 84: 316-323

\section{Introduction}

Cystic fibrosis (CF) is a life-limiting genetic disease involving multiple organ systems. About 30,000 individuals are presently living with $\mathrm{CF}$ in the United States (U.S.) and 70,000 worldwide [1]. The most common organ systems involved are respiratory and gastrointestinal system. Patients with CF experience chronic airway infection with progressive deterioration in pulmonary function as well as episodic pulmonary exacerbations [2, 3]. They often require inpatient care during these pulmonary exacerbations [4]. Patients with CF also suffer from other serious conditions like acute pancreatitis and liver disease, which might warrant or complicate inpatient care [5]. As a result, patients with CF have a high rate of hospitali- zation. The population prevalence of $\mathrm{CF}$ has been increasing despite fairly stable incidence due to longer survival as a result of improved quality of care. Based on the data from CF Foundation Patient Registry (CFFPR), the number of people with CF in the U.S. increased from 21,488 in 2003 to 28,134 in 2013 [1]. During the same period, the number of newly diagnosed individuals per year remained fairly stable $(1,044$ in 2003 and 1,039 in 2013).

The annual number of hospitalizations of individuals with CF is expected to increase with increasing prevalence. The factors affecting overall prognosis in $\mathrm{CF}$ are well defined, however, factors affecting in-hospital outcomes of patients with CF have not been studied in detail. Also, there is limited data on complications and outco-

Address for correspondence: Kshitij Chatterjee, MD, University of Arkansas for Medical Sciences 4301 W Markham Street, Little Rock, AR 72205. Department of Internal

Medicine, Residency Program: Slot 634, e-mail: kchatterjee@uams.edu

DOl: 10.5603/ARM.2016.0041

Received: 13.09 .2016

Copyright (C) 2016 PTChP

ISSN 2451-4934 
mes of hospitalized individuals with a prior lung transplant. In this study, we report the temporal national trends of hospitalizations of people with $\mathrm{CF}$ and their characteristics in the U.S. between 2003 and 2013. We also identify the burden of co -morbidities and complications among inpatients with CF and their impact on outcomes. Lastly, we examine the outcomes of hospitalized CF patients with a prior lung transplant.

\section{Material and methods}

\section{Data source}

The National Inpatient Sample (NIS) previously known as Nationwide Inpatient Sample is one of the databases developed for the Healthcare Cost and Utilization Project (HCUP) by the Agency of Healthcare Research and Quality (AHRQ) [6]. It is the largest inpatient database in the United States (U.S.) and has been used by researchers and policymakers to estimate healthcare utilization and outcomes. Prior to 2012, the data was obtained from a sample of hospitals from which all discharge records were retained to approximate discharges from a $20 \%$ stratified sample of all U.S. hospitals. Beginning in 2012, NIS was redesigned to contain a sample of discharges from all HCUP-participating hospitals across 44 states. NIS database now approximates $20 \%$ stratified sample of all discharges from all U.S. hospitals. Sampling weights are provided to produce national-level estimates. After redesigning the NIS, new sampling weights were created for trend analysis for the years before 2012 to account for the new design. Every hospitalization is de-identified and converted into one unique entry which provides demographic information (age, sex, race etc.), one primary and up to 24 secondary discharge diagnoses, length of stay, outcomes, and Elixhauser comorbidities [7]. The discharge diagnoses are provided in the form of International Classification of Diseases, $9^{\text {th }}$ Revision, Clinical Modification code (ICD-9$\mathrm{CM}$ ). This study did not require review from the Institutional Review Board (IRB).

\section{Study population}

Data from NIS between 2003 and 2013 was used to identify patients with CF (ICD-9-CM: 277.00-277.09). Full description of ICD-9-CM codes used for the study is provided in Table 1 . We excluded all cases with missing age and gender variables ( $0.3 \%$ of hospitalizations). Patients with prior lung transplant were identified by presence of codes for lung transplant (V42.6, 996.84) and lacking procedure codes of lung transplant surgery in that hospitalization. Acute kidney injury (AKI) was identified with diagnosis codes 584.5 to 584.9. Patients with AKI requiring dialysis (AKI-D) were identified using methods validated for use with administrative databases [8]. Other co-morbidities were identified by their respective ICD-9-CM codes as shown in Table 1.

\section{Statistical analysis}

Stata 13.1.0 (Stata Corp, College Station, TX) and SPSS 23.0 (SPSS Inc., Chicago, Ill) were used for all statistical analyses. Sampling weights provided by HCUP were used to produce national level estimates. Demographics, hospital characteristics, and outcomes of all cases with CF were obtained. Prevalence of various co-existing conditions and their mortality were calculated. $\chi 2$ test of trend for proportions was used with the Cochrane Armitage test through the "ptrend" command in Stata to determine statistical significance of trend for categorical variables [9]. Independent-Samples t-test and Chi-square test were used to determine statistical significance between groups. Multivariate logistic regression model was used to determine the adjusted impact of co-morbidities on in-hospital mortality. A 2 sided p-value of less than 0.05 was considered statistically significant.

\section{Results}

A total of 311,651 hospitalizations of patients with CF were reported in the U.S between 2003 and 2013. The number of hospitalizations per 1,000 CF patients in the U.S. increased from 994 in 2003 to 1,072 in 2013. The demographic characteristics and outcomes of the patients are summarized in Table 2. The mean age of all the hospitalized CF patients in our study was 22.3 years $(S D=13.4)$. The mean age of CF patients in community in the U.S. in 2013 was 20.2 [1]. This difference highlights the fact that older CF patients are hospitalized more often leading to a higher mean age of the hospitalized population. More women with CF were hospitalized compared to men, overall, as well as during individual years. Almost two-thirds of hospitalized CF patients were adults $\geq 18$ years of age). Overall, the median age at death was 27 years and in-hospital mortality was $1.5 \%$. The mortality among adults was $2 \%$ compared to $0.6 \%$ among individuals less than 18 years of age. There was no gender difference in mortality (1.5\% in each group). 


\section{Table 1. List of ICD-9-CM codes used in the study}

\begin{tabular}{ll}
\hline $\begin{array}{l}\text { Cystic fibrosis } \\
\text { Cystic fibrosis without mention of meconium } \\
\text { ileus }\end{array}$ & 277.00 \\
$\begin{array}{l}\text { Cystic fibrosis with meconium ileus } \\
\text { Cystic fibrosis with pulmonary manifestations }\end{array}$ & 277.01 \\
$\begin{array}{l}\text { Cystic fibrosis with gastrointestinal } \\
\text { manifestations }\end{array}$ & 277.03 \\
$\begin{array}{l}\text { Cystic fibrosis with other manifestations } \\
\text { Chronic non-alcoholic liver disease }\end{array}$ & 277.09 \\
$\begin{array}{l}\text { Cirrhosis of liver without mention of alcohol } \\
\text { Biliary cirrhosis }\end{array}$ & 571.5 \\
$\begin{array}{l}\text { Other chronic nonalcoholic liver disease } \\
\text { Unspecified chronic liver disease without } \\
\text { mention of alcohol }\end{array}$ & 571.6 \\
$\begin{array}{l}\text { Acute pancreatitis } \\
\text { Lung transplantation }\end{array}$ & 571.8 \\
$\begin{array}{l}\text { Hemodialysis } \\
\text { Lung transplant status }\end{array}$ & 571.9 \\
$\begin{array}{l}\text { Complications of transplanted lung } \\
\text { Acute kidney injury }\end{array}$ & 577.0 \\
$\begin{array}{l}\text { Acute kidney failure with lesion of tubular } \\
\text { necrosis } \\
\begin{array}{l}\text { Acute kidney failure with lesion of renal } \\
\text { cortical necrosis }\end{array}\end{array}$ & 584.5 \\
$\begin{array}{l}\text { Acute kidney failure with lesion of renal } \\
\text { medullary [papillary] necrosis } \\
\text { pathological lesion in kidney }\end{array}$ & 584.6 \\
\hline
\end{tabular}

The in-hospital mortality trended down from $1.9 \%$ in 2003 to $1.2 \%$ in 2013 (p-value for trend: 0.002) (Fig. 1). The median length of stay was 7 days (Interquartile range [IQR] $=10$ days) which remained fairly constant from 2003 through 2013.

Table 3 provides information on hospital characteristics, insurance, and discharge disposition for these patients. The majority of hospitalizations occurred in large sized teaching hospitals located in urban areas. About 21\% of patients were discharged with home health care, whereas, only about $3 \%$ required discharge to short or long term care facilities (including skilled nursing facility, intermediate care facility, and long term care hospital etc.).

\section{Co-existing conditions}

Table 4 reports the prevalence of AKI, acute pancreatitis, and chronic non-alcoholic liver disease among the hospitalized CF patients. AKI was reported in 11,792 (3.8\%) hospitalizations of CF patients. These patients were significantly older than those without AKI [32.1 \pm 13.8 ) vs $21.9 \pm 13.2$ ) years, $p<0.001$ ). $9.3 \%$ of cases with AKI required dialysis (AKI-D). A multivariate regression model was created to analyze the effect of AKI on in-hospital mortality. Covariates for the model included demographics (age, gender, race); all Elixhauser co-morbidities (excluding renal failure), hospital characteristics (teaching status, location, bed-size), and need for mechanical ventilation. After adjusting for these variables, the odds of in-hospital mortality with AKI was 1.74 (95\% CI 1.57-1.93, p < 0.001).

Underlying chronic liver disease was recorded in $3.7 \%$ of hospitalized CF patients. Acute pancreatitis was present in $1.7 \%$ of cases. Figure 2 demonstrates the distribution of hospitalizations by each calendar month.

\section{Lung transplant recipients}

Individuals with prior lung transplant constituted 20,112 (6.5\%) of all hospitalizations of patients with CF. These patients were significantly older compared to patients without transplant [30.5 ( \pm 11.0$)$ years vs $21.8( \pm 13.4)$ years, $\mathrm{p}<0.001)$. Table 5 provides the demographics, co-morbidities, primary discharge diagnosis, and outcomes of these patients. About $40 \%$ of these hospitalizations were related to complications of transplanted lungs. AKI occurred in $19.7 \%$ of transplanted patients compared to $2.7 \%$ without a transplant ( $p<0.001) .11 .2 \%$ of transplant patients with AKI required dialysis. Figure 1 provides a graphical display of temporal trend of mortality among individuals with lung transplant.

\section{DISCUSSION}

This study reports the data of hospitalizations of CF patients using a large, nationally representative sample of the U.S. population. The results indicate that annual number of hospitalizations of patients with CF is increasing over the last decade which is in part due to the rising prevalence of CF in the U.S. Even after adjusting 
Table 2. Clinical characteristics and outcomes of hospitalized patients with cystic fibrosis from 2003 through 2013

\begin{tabular}{|c|c|c|c|c|c|c|c|c|c|c|c|c|}
\hline Year & 2003 & 2004 & 2005 & 2006 & 2007 & 2008 & 2009 & 2010 & 2011 & 2012 & 2013 & Overall \\
\hline Observations, N & 21,355 & 23,354 & 33,113 & 24,700 & 25,262 & 32,173 & 25,117 & 33,642 & 33,175 & 29,605 & 30,155 & 311,651 \\
\hline $\begin{array}{l}\text { Mean age } \\
\text { (SD), years }\end{array}$ & $\begin{array}{c}20.9 \\
(12.7)\end{array}$ & $\begin{array}{c}20.9 \\
(13.1)\end{array}$ & $\begin{array}{c}19.9 \\
(12.4)\end{array}$ & $\begin{array}{c}21.7 \\
(13.2)\end{array}$ & $\begin{array}{c}22.3 \\
(13.4)\end{array}$ & $\begin{array}{c}23.2 \\
(13.2)\end{array}$ & $\begin{array}{c}23.5 \\
(13.8)\end{array}$ & $\begin{array}{c}21.8 \\
(13.3)\end{array}$ & $\begin{array}{c}24.0 \\
(13.5)\end{array}$ & $\begin{array}{c}23.1 \\
(13.9)\end{array}$ & $\begin{array}{c}23.6 \\
(14.1)\end{array}$ & $\begin{array}{c}22.3 \\
(13.4)\end{array}$ \\
\hline \multicolumn{13}{|l|}{$\begin{array}{l}\text { Distribution } \\
\text { by age, } \%\end{array}$} \\
\hline Age $\geq 18$ years & 59.3 & 59.3 & 54.8 & 61.1 & 63.5 & 67.3 & 69.1 & 61.2 & 69.9 & 65.6 & 66.8 & 63.6 \\
\hline Age $<18$ years & 40.7 & 40.7 & 45.2 & 38.9 & 36.5 & 32.7 & 30.9 & 38.8 & 30.1 & 34.4 & 33.2 & 36.4 \\
\hline \multicolumn{13}{|l|}{ Gender, \% } \\
\hline Male & 46.9 & 47.4 & 47.9 & 44.6 & 44.8 & 44.4 & 46.6 & 44.9 & 45.3 & 46.3 & 45.3 & 45.8 \\
\hline Female & 53.1 & 52.6 & 52.1 & 55.4 & 55.2 & 55.6 & 53.4 & 55.1 & 54.7 & 53.7 & 54.7 & 54.2 \\
\hline $\begin{array}{l}\text { In-hospital } \\
\text { mortality, \% }\end{array}$ & 1.9 & 1.5 & 1.4 & 1.4 & 1.6 & 1.7 & 1.5 & 1.4 & 1.6 & 1.5 & 1.2 & 1.5 \\
\hline \multicolumn{13}{|l|}{$\begin{array}{l}\text { Mortality } \\
\text { (by gender), \% }\end{array}$} \\
\hline Male & 1.9 & 1.5 & 1.3 & 1.3 & 1.7 & 1.9 & 1.5 & 1.4 & 1.6 & 1.3 & 1.4 & 1.5 \\
\hline Female & 1.8 & 1.5 & 1.5 & 1.5 & 1.4 & 1.6 & 1.6 & 1.5 & 1.6 & 1.6 & 1.1 & 1.5 \\
\hline \multicolumn{13}{|l|}{$\begin{array}{l}\text { Mortality } \\
\text { (by age), \% }\end{array}$} \\
\hline Age $<18$ & 0.7 & 0.5 & 0.7 & 0.7 & 0.7 & 0.5 & 0.5 & 0.5 & 0.6 & 0.8 & 0.5 & 0.6 \\
\hline Age $\geq 18$ & 2.7 & 2.2 & 1.9 & 1.9 & 2.1 & 2.3 & 2 & 2 & 2 & 1.8 & 1.6 & 2.0 \\
\hline $\begin{array}{l}\text { Median age } \\
\text { at death (IQR) }\end{array}$ & $\begin{array}{c}27 \\
(13)\end{array}$ & $\begin{array}{c}28 \\
(17)\end{array}$ & $\begin{array}{c}23 \\
(14)\end{array}$ & $\begin{array}{c}24 \\
(11)\end{array}$ & $\begin{array}{l}27 \\
(20)\end{array}$ & $\begin{array}{c}27 \\
(14)\end{array}$ & $\begin{array}{c}27 \\
(18)\end{array}$ & $\begin{array}{c}25 \\
(18)\end{array}$ & $\begin{array}{c}29 \\
(15)\end{array}$ & $\begin{array}{c}27 \\
(17)\end{array}$ & $\begin{array}{c}27 \\
(18)\end{array}$ & $\begin{array}{c}27 \\
(16)\end{array}$ \\
\hline $\begin{array}{l}\text { Median LOS (IOR), } \\
\text { days }\end{array}$ & $\begin{array}{c}7 \\
(10)\end{array}$ & $\begin{array}{c}6 \\
\text { (9) }\end{array}$ & $\begin{array}{c}7 \\
(10)\end{array}$ & $\begin{array}{c}7 \\
(10)\end{array}$ & $\begin{array}{c}7 \\
\text { (9) }\end{array}$ & $\begin{array}{c}7 \\
\text { (9) }\end{array}$ & $\begin{array}{c}7 \\
(10)\end{array}$ & $\begin{array}{c}8 \\
(9)\end{array}$ & $\begin{array}{c}7 \\
(11)\end{array}$ & $\begin{array}{c}7 \\
(10)\end{array}$ & $\begin{array}{c}7 \\
\text { (9) }\end{array}$ & $\begin{array}{c}7 \\
(10)\end{array}$ \\
\hline
\end{tabular}

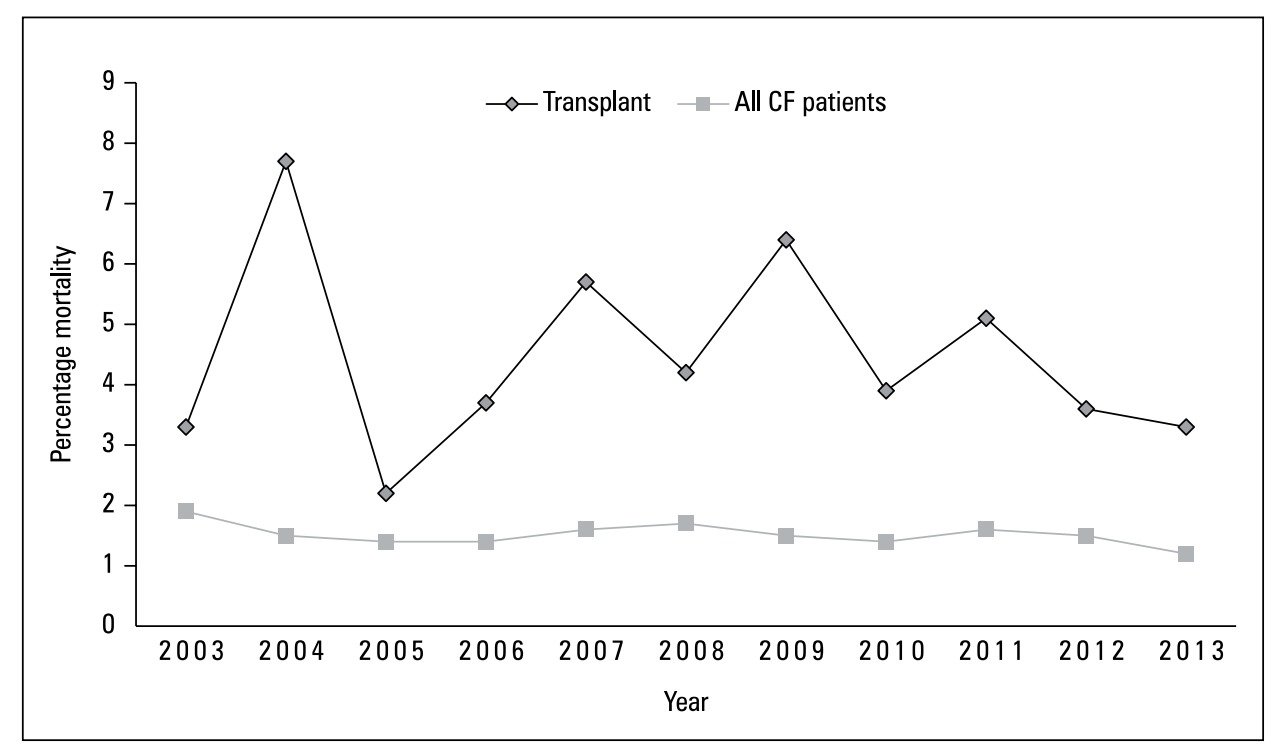

Figure 1. National temporal trends of in-hospital mortality among hospitalized cystic fibrosis patients. Dark grey line represents CF patients with prior lung transplant. Light gray line represents all hospitalized CF patients 
Table 3. Hospital characteristics, insurance, and discharge disposition of the hospitalized cystic fibrosis patients

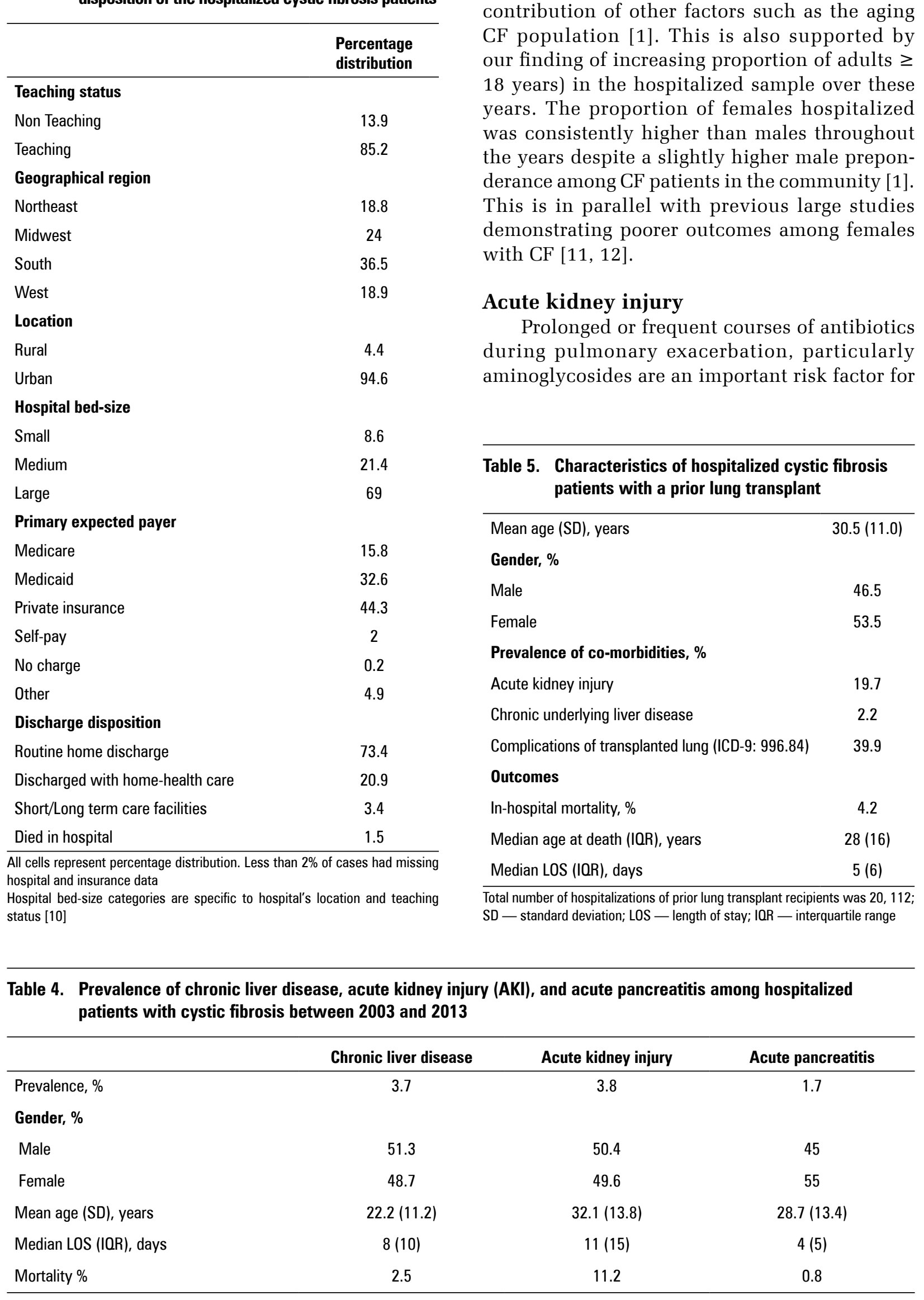
still trended up during this period indicating contribution of other factors such as the aging CF population [1]. This is also supported by our finding of increasing proportion of adults $\geq$ 18 years) in the hospitalized sample over these years. The proportion of females hospitalized was consistently higher than males throughout the years despite a slightly higher male preponderance among CF patients in the community [1]. This is in parallel with previous large studies demonstrating poorer outcomes among females Acute kidney injury

Prolonged or frequent courses of antibiotics .

for prevalence, the annual hospitalization rates 
patients [13]. Pseudomonas and Staphylococcus aureus are the two most common respiratory microorganisms isolated among individuals with CF $[1,14]$. Simultaneous utilization of multiple antimicrobial agents during a pulmonary exacerbation is often required due to the increasing prevalence of multidrug resistance among these organisms $[15,16]$. Patients with AKI were found to be significantly older in our study, which might be a risk factor for its development. Nephrotoxic immunosuppressive agent use in transplant recipients is another factor potentially contributing to acute or chronic renal dysfunction [17]. Our study presents the novel finding that even after adjusting for multiple variables, the mortality of patients with CF who develop AKI is significantly higher compared to those without AKI. Considering the burden of AKI and its significant impact on outcomes in hospitalized CF population, improvement in antibiotic stewardship program is warranted. Other considerations would be to monitor the renal function of these patients even more closely during an exacerbation. According to current 'Cystic Fibrosis Pulmonary Guidelines' on treatment of pulmonary exacerbation, there is insufficient data on equivalence of home vs hospital treatment [4]. As there is only limited data on differences in occurrence of renal dysfunction between the treatment sites $[18,19]$ the ability to monitor renal function frequently should play an important role when considering the site of treatment for an exacerbation. In light of our data, another randomized controlled trial is needed evaluating differences in renal outcomes between these sites.

\section{Patients with prior lung transplantation}

Patients with prior lung transplantation constituted a significant proportion (6.5\%) of hospitalizations in our study. $90 \%$ of these were adults (age $\geq 18$ years). Recent literature demonstrated that mean age of patients with CF undergoing lung transplantation is increasing [20]. The same study by Kimura et al. [20] also reported that the proportion of lung transplantations performed for CF has decreased over time and this trend is particularly pronounced in pediatric population. In the current sample of hospitalized transplanted patients, about $40 \%$ admissions were directly related to complications of lung transplantation. Further data on nature of complication could not be obtained due to non-specificity of ICD-9 codes for post transplant complications like bronchiolitis obliterans syndrome and graft failure. Renal dysfunction is a common long-term complica- tion of lung transplant [21]. Our study focuses only on acute kidney injury and those requiring dialysis in the setting of AKI. Our data suggests that about one in five hospitalized CF patient with prior lung transplantation suffers from AKI and every one in ten patients with AKI requires dialysis. This is associated with higher mortality in transplanted individuals as demonstrated previous studies [22].

\section{Seasonal variation}

There was some variation in the burden of admissions between meteorological seasons [23]. The overall number of admissions in the winter months was higher than summer months. Lowest number of admissions were recorded in May; the burden of admissions increased through fall to reach a peak in February (Fig. 2). However, as the study sample was nationally representative and distributed through 44 states, it was difficult to ascertain the impact of ambient temperature on frequency of admissions of patients with cystic fibrosis [6]. There is limited data in literature on association of seasonal variation with pulmonary exacerbations [24, 25].

\section{Limitations}

Several limitations of our study need to be acknowledged. As with any administrative database, it was not possible to control for coding errors and reporting bias. The accuracy of ICD-9$\mathrm{CM}$ codes to identify cases with $\mathrm{CF}$ has not been specifically tested in NIS. Although, use of all ICD-9-CM codes from 277.00 to 277.09 likely increased our sensitivity in identifying CF patients, the accuracy remains uncertain. However, the fair consistency of demographics and outcomes between our CF population and CFFPR indicates a well selected study population. Similarly, codes used for identifying AKI-D were well validated to use with an administrative database. Secondly, some factors predicting severity of pulmonary disease like $\mathrm{FEV}_{1}$ were not available. Lastly, as NIS provides each hospitalization as a separate entry without a unique patient identifier, it was not possible to identify readmissions separately. Despite these limitations, our study highlights important trends in patients hospitalized with $\mathrm{CF}$ using a large, nationally representative database.

\section{Conclusions}

In conclusion, our study demonstrates the recent national trends of hospitalizations of individuals with $\mathrm{CF}$ and co-morbidities in the 


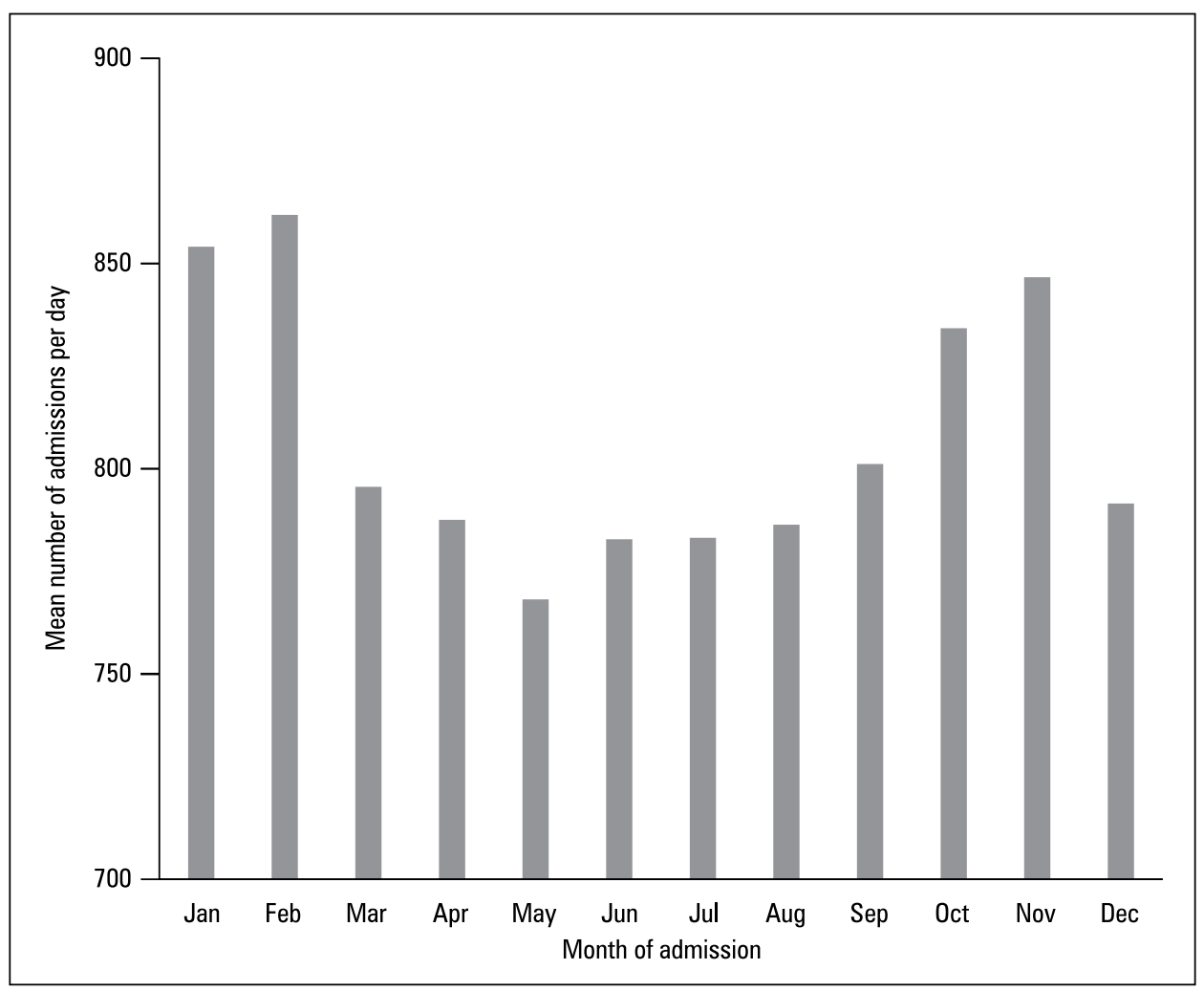

Figure 2. Distribution of admissions of patients with cystic fibrosis through calendar months. Each bar represents mean number of admission per day in a month

United States. Overall all-cause mortality has significantly decreased over this period. Median age at death in hospital and length of stay did not change significantly over the 11-year period. Acute kidney injury is an important co-morbidity with significant impact on mortality. These results should be helpful for developing guidelines to improve quality of inpatient care, decreasing iatrogenic complications, providing valuable prognostic information, and identifying new challenges in the management of the increasing population of individuals with cystic fibrosis.

\section{Conflict of interest}

The authors declare no conflict of interest.

\section{References:}

1. CF Patient Registry Reports, https://www.cff.org/Our-Research/ /CF-Patient-Registry/CF-Patient-Registry-Reports/; 25.09.2015.

2. Ratjen F, Döring G. Cystic fibrosis. Lancet 2003; 361: 681-689.

3. Ramsey BW. Management of pulmonary disease in patients with cystic fibrosis. N Engl J Med 1996; 335: 179-188.

4. Flume PA, Mogayzel PJ, Robinson KA et al. Cystic fibrosis pulmonary guidelines: treatment of pulmonary exacerbations. Am J Respir Crit Care Med 2009; 180: 802-808.

5. Park RW, Grand RJ. Gastrointestinal manifestations of cystic fibrosis: a review. Gastroenterology 1981; 81: 1143-1161.

6. HCUP-US NIS Overview, https://www.hcup-us.ahrq.gov/ /nisoverview.jsp; 23.04.2016.
7. Elixhauser A, Steiner C, Harris DR, Coffey RM. Comorbidity measures for use with administrative data. Med Care 1998; 36: 8-27.

8. Waikar SS, Wald R, Chertow GM et al. Validity of international classification of diseases, ninth revision, clinical modification codes for acute renal failure. J Am Soc Nephrol 2006; 17: 1688-1694.

9. Armitage P. Tests for linear trends in proportions and frequencies. Biometrics 1955; 11: 375-386.

10. Healthcare Cost and Utilization Project (HCUP) NIS Notes [Internet], https://www.hcup-us.ahrq.gov/db/vars/hosp_bedsize/ nisnote.jsp; 25.04.2016.

11. Harness-Brumley CL, Elliott AC, Rosenbluth DB, Raghavan D, Jain R. Gender differences in outcomes of patients with cystic fibrosis. J Womens Health (Larchmt) 2014; 23: 1012-1020.

12. Rosenfeld M, Davis R, FitzSimmons S, Pepe M, Ramsey B. Gender gap in cystic fibrosis mortality. Am J Epidemiol 1997; 145: 794-803.

13. Downes KJ, Patil NR, Rao MB et al. Risk factors for acute kidney injury during aminoglycoside therapy in patients with cystic fibrosis. Pediatr Nephrol 2015; 30: 1879-1888.

14. Goss CH, Muhlebach MS. Review: Staphylococcus aureus and MRSA in cystic fibrosis. J Cyst Fibros 2011; 10: 298-306.

15. Lister PD, Wolter DJ, Hanson ND. Antibacterial-resistant Pseudomonas aeruginosa: clinical impact and complex regulation of chromosomally encoded resistance mechanisms. Clin Microbiol Rev 2009; 22: 582-610.

16. Ren CL, Konstan MW, Yegin A et al. Multiple antibiotic-resistant Pseudomonas aeruginosa and lung function decline in patients with cystic fibrosis. J Cyst Fibros 2012; 11: 293-299.

17. Nazareth D, Walshaw M. A review of renal disease in cystic fibrosis. J Cyst Fibros 2013; 12: 309-317.

18. Wolter JM, Bowler SD, Nolan PJ, McCormack JG. Home intravenous therapy in cystic fibrosis: a prospective randomized trial examining clinical, quality of life and cost aspects. Eur Respir J 1997; 10: 896-900. 
19. Balaguer A, González de Dios J. Home versus hospital intravenous antibiotic therapy for cystic fibrosis. Cochrane database Syst Rev 2012; 3: CD001917.

20. Kimura N, Khan MS, Schecter M et al. Changing demographics and outcomes of lung transplantation recipients with cystic fibrosis. J Hear Lung Transplant 2016; 35: 1237-1244

21. Lyu DM, Zamora MR. Medical complications of lung transplantation. Proc Am Thorac Soc 2009; 6: 101-107.

22. George TJ, Arnaoutakis GJ, Beaty CA et al. Acute kidney injury increases mortality after lung transplantation. Ann Thorac Surg 2012; 94: 185-192.
23. Meteorological Versus Astronomical Summer - What's the Difference? | National Centers for Environmental Information (NCEI) formerly known as National Climatic Data Center (NCDC), https:// //www.ncdc.noaa.gov/news/meteorological-versus-astronomical -summer\%E2\%80\%94what\%E2\%80\%99s-difference; 25.04.2016.

24. Smith W.D, Wilmot J.K.A JNA. 228 Seasonal variation in the number or the severity of pulmonary exacerbations in adult CF patients. J Cyst Fibros 2005; 4: S60.

25. Johansen HK, Høiby N. Seasonal onset of initial colonisation and chronic infection with Pseudomonas aeruginosa in patients with cystic fibrosis in Denmark. Thorax 1992; 47: 109-111. 